\title{
Optimalisasi Desain Instalasi Pengolahan Air Limbah Tempat Pemrosesan Akhir Talang Gulo Lama
}

Febri Revelino Sitorus ${ }^{1)}$, Freddy Ilfan ${ }^{1)}$, Winny Laura Christina Hutagalung ${ }^{1)}$

${ }^{1}$ Program Studi Teknik Lingkungan, Fakultas Teknik, Universitas Jambi

Email: febrirevelino@gmail.com, freddy_ilfan@unja.ac.id, winnylaura@yahoo.co.id

\section{Info Artikel}

Diterima: 19 Desember 2019

Disetujui: 14 Januari 2020

Dipublikasikan: 31 Januari 2020

\section{Alamat Korespondensi: \\ febrirevelino@gmail.com \\ Copyright (C) 2020 Jurnal Engineering}

This work is licensed under the Creative Commons Attribution International License (CC BY 4.0).

\begin{abstract}
Abstrak
Lindi yang merupakan air limbah dari timbulan sampah dan mengandung mikroorganisme, bahan organik, dan anorganik yang berpotensi mencemari air dan tanah sekitar TPA. Kualitas lindi dapat dipengaruhi oleh faktor komposisi timbulan sampah serta lamanya timbulan sampah. Penelitian ini bertujuan menghitung debit lindi yang dihasilkan di TPA Talang Gulo Lama, mengkaji kualitas lindi TPA Talang Gulo Lama yang meliputi parameter BOD, COD, dan TSS, serta merancang unit pengolahan untuk mengoptimalisasi IPAL TPA Talang Gulo Lama. Dengan menggunakan Metode Neraca Air (Water Balance Method) oleh Thorntwaite, perkolasi tertinggi yaitu $86,8 \mathrm{~mm} /$ bulan atau $0,086 \mathrm{~m} /$ bulan, sehingga debit air lindi di TPA Talang Gulo Lama adalah $249,4 \mathrm{~m}^{3} /$ hari atau $0,0029 \mathrm{~m}^{3} / \mathrm{s}$. Dari hasil analisis sampel lindi TPA Talang Gulo Lama, diketahui bahwa kualitas parameter COD, BOD, dan TSS adalah masing-masing $2.406 \mathrm{mg} / \mathrm{L}, 1.046 \mathrm{mg} / \mathrm{L}$, dan 440 mg/L. Dengan menggunakan proses pengolahan Anaerobic Baffled Reactor persentase penyisihan tiap parameter dapat mencapai $80 \%$ dan pengolahan menggunakan Aerated Lagoon persentase penyisihan hingga 90\%. Sehingga efluen IPAL menjadi $48,12 \mathrm{mg} / \mathrm{L}$ (COD); 30,93 $\mathrm{mg} / \mathrm{L}$ (BOD); 8,8 mg/L (TSS) dan telah memenuhi kriteria baku mutu menurut Peraturan Menteri Lingkungan Hidup dan Kehutanan RI Nomor 59 Tahun 2016.

Kata kunci: Aerated Lagoon; Anaerobic Baffled Reactor; lindi; Tempat Pemrosesan Akhir
\end{abstract}

\section{Pendahuluan}

Lindi menjadi masalah yang timbul akibat pengoperasian TPA yang harus dikelola, karena hal ini sangat berpengaruh terhadap kondisi tanah dan air yang ada di sekitar TPA. Tercemarnya air dan 
tanah oleh lindi menyebabkan pertumbuhan bakteri dan reaksi kimia yang berdampak terhadap kualitas air dan tanah. Kualitas lindi sangat dipengaruhi oleh usia limbah karena dampaknya terhadap pertumbuhan bakteri dan reaksi kimia dalam limbah (Lee, dkk 2010).

TPA Talang Gulo lama dengan umur operasi 21 tahun dan $\mathrm{pH}$ 8,1 menghasilkan lindi yang termasuk tipe stabil. Namun BOD/COD TPA Talang Gulo lama termasuk dalam klasifikasi Muda karena $\mathrm{BOD} / \mathrm{COD}=168 / 1403=0,11$. Maka berdasarkan kajian tersebut, TPA Talang gulo lama memerlukan pengolahan tambahan atau modifikasi dari pengolahan lindi yang telah ada.

Anaerobic Baffled Reactor merupakan pengolahan air limbah dengan sistem tangki septik, dengan penambahan sistem penyekatan di dalam tangkinya. ABR terdiri dari penyekatan yang berdiri dan menggantung secara bergantian dimana ada pembagian ruangan-ruangan reaktor dengan aliran ke atas dan ke bawah dari ruangan satu ke ruang berikutnya. Tangki septik adalah suatu ruangan kedap air atau beberapa kompartemen ruangan, yang berfungsi menampung/mengolah air limbah dengan aliran yang lambat, sehingga akan terjadi pengendapan terhadap suspensi benda-benda padat dan penguraian oleh mikroorganisme yang membentuk larutan dan gas. Efisiensi penghilangan COD sekitar 65\% - 90\% dan BOD sekitar (70\% - 95\%) (Sasse et al., 2009).

Aerated Lagoon adalah unit proses pengolahan air limbah dengan memanfaatkan mikroorganisme tersuspensi tanpa menggunakan resirkulasi lumpur, pemompaan udara pada kolam oksidasi dilakukan dengan menggunakan aerator. Kolam aerasi dikembangkan dari kolam oksida fakultatif yang ditambahkan aerator untuk mencegah bau yang timbul. Sebelum effluen dibuang, padatan sudah harus dihilangkan sebelum melalui proses pengendapan. Tahap ini ditandai dengan adanya proses aerasi yang bertujuan untuk mengontakkan semaksimal mungkin pemakaian cairan dengan udara, agar transfer sesuatu zat atau komponen dari satu medium ke medium lain berlangsung lebih efisien. (Metcalf dan Eddy, 1991)

\section{Metode Penelitian}

Penelitian ini dilaksanakan di TPA Talang Gulo lama di Jalan Kebersihan Kelurahan Kenali Asam Bawah Kecamatan Kota Baru Kota Jambi. Dengan koordinat lokasi adalah $1^{\circ} 41^{\prime} 18,46^{\prime \prime}$ Lintang Selatan dan $103^{\circ} 37^{\prime} 6,54^{\prime \prime}$ Bujur Timur. Penelitian ini telah berlangsung dari tanggal Oktober 2018 hingga Januari 2019.

Penelitian dengan judul "Optimalisasi Desain Instalasi Pengolahan Air Limbah Tempat Pemrosesan Akhir Talang Gulo Lama” ini telah selesai dalam waktu 11 minggu.

Analisis Debit Rencana Leachate

Q $\quad=\mathrm{K} \times(0,278 \times \mathrm{C} \times \mathrm{I} \times \mathrm{A})$

dengan:

$\mathrm{Q}=$ debit rencana leachate $\left(\mathrm{m}^{3} /\right.$ hari $)$

$\mathrm{K}=$ faktor pendekatan $(0,60-0,70)$

$\mathrm{C}=$ koefisien pengaliran $(0,3-0,4)$

I $\quad=$ intensitas hujan ( $\mathrm{mm} /$ hari)

A = luas galian tempat timbulan sampah

Metode Neraca Air (Water Balance Method) oleh Thorntwaite

$\mathrm{PERC} \quad=\mathrm{P}-(\mathrm{RO})-(\mathrm{AET})-(\Delta \mathrm{ST})$ 


\section{Hasil Penelitian dan Pembahasan}

Perhitungan debit air lindi menggunakan metode Neraca Air Thorntwaite Berdasarkan data pada data curah hujan dan hari hujan pos hujan Sultan Thaha Jambi dan data temperatur udara Stasiun BMKG Sultan Thaha Jambi, dapat menjadi acuan dalam perhitungan debit air lindi TPA Talang Gulo lama menggunakan metode Neraca Air Thorntwaite. Luas Tempat Pemrosesan Akhir Talang Gulo Lama adalah $8,7 \mathrm{Ha}$ atau seluas $87000 \mathrm{~m}^{2}$. Perkolasi tertinggi terjadi pada bulan desember, yaitu 86,8 $\mathrm{mm} /$ bulan atau 0,086 m/bulan Sehingga debit air lindi di TPA Talang Gulo Lama dapat dihitung melalui luas TPA dikalikan dengan perkolasi, menjadi 87000 x 0,086 adalah $7482 \mathrm{~m}^{3} /$ bulan atau 249,4 $\mathrm{m}^{3} /$ hari atau $0,0029 \mathrm{~m}^{3} / \mathrm{s}$.

Tabel 1 Hasil Analisis Sampel Lindi TPA Talang Gulo Lama

\begin{tabular}{ccccc}
\hline No. & Parameter & Satuan & Hasil Uji & Baku Mutu* $^{*}$ \\
\hline 1. & $\mathrm{pH}$ & - & 7,79 & $6-9$ \\
2. & Suhu & ${ }^{\circ} \mathrm{C}$ & 28,8 & - \\
3. & $\mathrm{COD}$ & $\mathrm{mg} / \mathrm{l}$ & 2406 & 300 \\
4. & $\mathrm{BOD}$ & $\mathrm{mg} / \mathrm{l}$ & 1046 & 150 \\
5. & $\mathrm{TSS}$ & $\mathrm{mg} / \mathrm{l}$ & 440 & 100 \\
\hline
\end{tabular}

* PerMen LHK RI Nomor 59 Tahun 2016

Sumber: Laboratorium DLH Provinsi Jambi 2018

Dari hasil pada tabel 1, untuk dapat menghasilkan parameter sesuai dengan baku mutu, perlu adanya pengolahan yang tepat untuk dapat meningkatkan kualitas air lindi. Bahan pencemar yang terkandung dalam air lindi perlu dikurangi hingga tidak menyebabkan pencemaran pada lingkungan.

Hasil Perhitungan Persentase Penyisihan dan Dimensi Kolam

Anaerobic Baffled Reactor

Tabel 2. Penyisihan pada Anaerobic Baffled Reactor

\begin{tabular}{ccccc}
\hline Parameter & $\begin{array}{c}\text { Influen } \\
\left(\mathrm{kg} / \mathrm{m}^{3}\right)\end{array}$ & $\begin{array}{c}\text { Organik } \\
\text { Loading } \\
\left(\mathrm{kg} / \mathrm{m}^{2} / \text { hari }\right)\end{array}$ & $\begin{array}{c}\text { Efluen } \\
(\mathrm{mg} / \mathrm{L})\end{array}$ & $\begin{array}{c}\% \\
\text { Penyisihan }\end{array}$ \\
\hline COD & 2,406 & 9,7443 & 481,2 & $80 \%$ \\
BOD & 1,046 & 4,2363 & 209,2 & $80 \%$ \\
TSS & 0,44 & 1,782 & 88 & $80 \%$ \\
\hline
\end{tabular}

Aerated Lagoon

Tabel 3. Penyisihan pada Aerated Lagoon

\begin{tabular}{ccccc}
\hline Parameter & $\begin{array}{c}\text { Organik Loading } \\
\left(\mathrm{kg} / \mathrm{m}^{2} / \mathrm{hari}\right)\end{array}$ & $\begin{array}{c}\text { Influen } \\
\left(\mathrm{kg} / \mathrm{m}^{3}\right)\end{array}$ & $\begin{array}{c}\text { Persentase } \\
\text { Penyisihan }\end{array}$ & Efluen $(\mathrm{mg} / \mathrm{L})$ \\
\hline COD & 0,798 & 0,481 & $90 \%$ & 48,12 \\
BOD & 0,347 & 0,209 & $90 \%$ & 20,92 \\
TSS & 0,145 & 0,088 & $90 \%$ & 8,8 \\
\hline
\end{tabular}


Rekapitulasi dimensi bak dan kolam yang dibutuhkan untuk mengoptimalisasi pengolahan lindi di TPA Talang Gulo lama dapat dilihat pada Tabel 4.

Tabel 4. Dimensi Kolam

\begin{tabular}{ccc}
\hline Dimensi & V Bak Anaerobic & V Kolam Aerated Lagoon \\
\hline $\mathrm{P}$ & $8 \mathrm{~m}$ & $12,5 \mathrm{~m}$ \\
$\mathrm{~L}$ & $12 \mathrm{~m}$ & $12,5 \mathrm{~m}$ \\
$\mathrm{~T}$ & $2,3 \mathrm{~m}$ & $6,2 \mathrm{~m}$ \\
\hline
\end{tabular}

\section{Kesimpulan}

Kesimpulan dari penelitian ini adalah sebagai berikut:

- Instalasi Pengolahan Air Limbah Tempat Pemrosesan Akhir Talang Gulo lama menerima debit air lindi sebanyak 0,003 $\mathrm{m} 3 /$ detik atau $259,2 \mathrm{~m} 3 /$ hari.

- Dari hasil pengujian laboratorium, sampel air lindi Instalasi Pengolahan Air Limbah Tempat Pemrosesan Akhir Talang Gulo diketahui hasil inlet COD $2.406 \mathrm{mg} / \mathrm{l}$ BOD $1.046 \mathrm{mg} / \mathrm{l}$ dan TSS $440 \mathrm{mg} / \mathrm{l}$.

- Dengan menggunakan proses pengolahan Anaerobic Baffled Reactor persentase penyisihan tiap parameter dapat mencapai $80 \%$ dan pengolahan menggunakan Aerated Lagoon persentase penyisihan hingga 90\%, sehingga efluen yang dihasilkan 48,12 mg/L (COD); 30,93 $\mathrm{mg} / \mathrm{L}$ (BOD); dan $8,8 \mathrm{mg} / \mathrm{L}$ (TSS).

\section{Daftar Pustaka}

[1] Lee A.H., Nikraz H., Hung Y. T. 2010. Influence of waste age on landfill leachate quality. International Journal of environmental science and development,1 (4):347-350.

[2] Metcalf dan Eddy., 1991. Wastewater Engineering : Treatment, Disposal, and Reuse. Mc Graw Hill Book Co.: Singapore

[3] Sasse, L., 1998. DEWATS: Decentralised Wastewater Treatment in Developing Countries. BORDA: Delhi. 